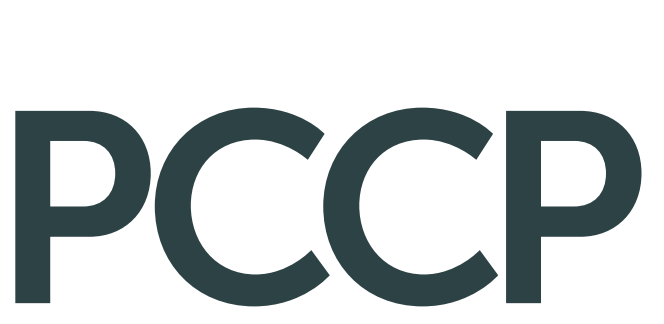

Physical Chemistry Chemical Physics rsc.li/pccp

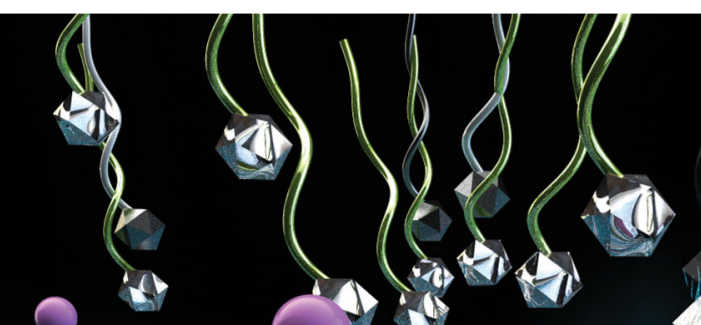

0
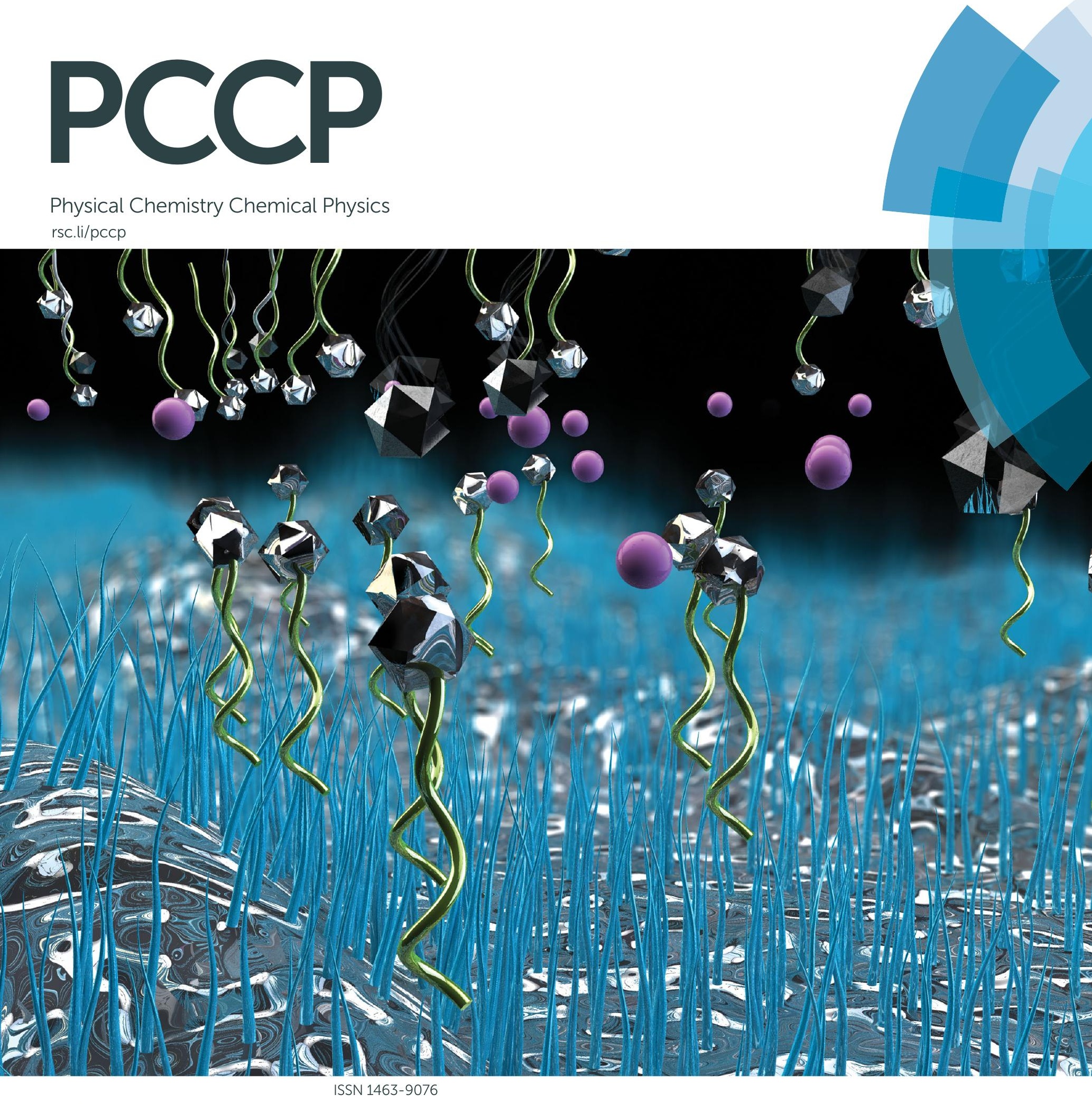


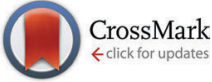

Cite this: Phys. Chem. Chem. Phys., 2017, 19, 5727

Received 27th October 2016 Accepted 17th November 2016

DOI: $10.1039 / c 6 c p 07351 d$

www.rsc.org/pccp

\section{Achieving enhanced ionic mobility in nanoporous silica by controlled surface interactions $\dagger$}

\author{
Mounesha Nagendrachar Garaga, ${ }^{a}$ Luis Aguilera, ${ }^{\mathrm{b}}$ Negin Yaghini, ${ }^{\mathrm{a}}$ \\ Aleksandar Matic, ${ }^{b}$ Michael Persson ${ }^{c}$ and Anna Martinelli*a
}

\begin{abstract}
We report a strategy to enhance the ionic mobility in an emerging class of gels, based on robust nanoporous silica micro-particles, by chemical functionalization of the silica surface. Two very different ionic liquids are used to fill the nano-pores of silica at varying pore filling factors, namely one aprotic imidazolium based (1-methyl-3-hexylimidazolium bis(trifluoromethanesulfonyl)imide, $\mathrm{C}_{6} \mathrm{C}_{1} \mathrm{ImTFSI}$ ), and one protic ammonium based (diethylmethylammonium methanesulfonate, DEMAOMs) ionic liquid. Both these ionic liquids display higher ionic mobility when confined in functionalized silica as compared to untreated silica nano-pores, an improvement that is more pronounced at low pore filling factors (i.e. in the nano-sized pore domains) and observed in the whole temperature window investigated (i.e. from -10 to $140{ }^{\circ} \mathrm{C}$ ). Solid-state NMR, diffusion NMR and dielectric spectroscopy concomitantly demonstrate this effect. The origin of this enhancement is explained in terms of weaker intermolecular interactions and a consequent flipped-ion effect at the silica interface strongly supported by 2D solidstate NMR experiments. The possibility to significantly enhance the ionic mobility by controlling the nature of surface interactions is extremely important in the field of materials science and highlights these structurally tunable gels as promising solid-like electrolytes for use in energy relevant devices. These include, but are not limited to, Li-ion batteries and proton exchange membrane (PEM) fuel cells.
\end{abstract}

\section{Introduction}

Ionic conduction, i.e. the motion of charged species within a solid or liquid material, is the basis of many important biological and chemical processes. ${ }^{1}$ Understanding the mechanism by which ions move within a porous host structure, and in particular how this relates to the chemical surroundings, is not only pivotal to the design of new functional materials but also to further develop technologies with potential for a societal impact. In this field of materials science, an important challenge is achieving selective ion conduction to suit a specific application. Although several materials display high ionic conductivity in their liquid state, many energy relevant technologies require solid-state electrolytes. ${ }^{2-4}$ The development of such materials is challenging since the incorporation of a liquid into a solid host material has the direct effect of reducing the ionic mobility ${ }^{5,6}$

\footnotetext{
${ }^{a}$ Department of Chemistry and Chemical Engineering, Kemigården 4, 41296 Gothenburg, Sweden. E-mail: anna.martinelli@chalmers.se

${ }^{b}$ Department of Physics, Origovägen 6B, 41296 Gothenburg, Sweden

${ }^{c}$ AkzoNobel, Pulp and Performance Chemicals, Bohus, Sweden

$\dagger$ Electronic supplementary information (ESI) available: The file contains additional experimental data obtained by ${ }^{1} \mathrm{H}$ and ${ }^{13} \mathrm{C}$ NMR spectroscopy, 2D HETCOR MAS solid state NMR spectroscopy, and Raman spectroscopy. The results of TGA and DSC measurements are also provided. See DOI: 10.1039/c6cp07351d
}

and altering other physicochemical properties. ${ }^{7}$ Strategies are therefore needed to minimize these effects. ${ }^{8}$

The development of solid-state electrolytes is crucial for the PEM fuel cell, an electrochemical device that produces clean electricity and is as such highlighted in the context of creating a sustainable energy system. The archetypical PEM material is a perfluorinated polymer (e.g. Nafion) that typically displays very high conductivities at temperatures below $80{ }^{\circ} \mathrm{C}$ and at high hydration levels. Due to dehydration, however, this type of material is not suitable for the higher temperature range targeted for next-generation PEM fuel cell electrolytes, that is above $120^{\circ} \mathrm{C}$. This target on the other hand can be reached by ionic liquids, unique electrolytes, ${ }^{9}$ which due to their low volatility can provide high ionic conductivities at elevated temperaturesł thus opening new frontiers in materials science. ${ }^{10}$ Ionic liquids are defined as molecular salts with a melting temperature below $100{ }^{\circ} \mathrm{C}$ (which in many cases is in fact below room temperature) and generally comprise bulky asymmetric ions. Because an ionic liquid acts simultaneously as the solvent and the charge carrier, the charge density is very high. As for conventional electrolytes, and also with ionic liquids, a main scientific challenge

$\ddagger$ The thermal stability of imidazolium based ionic liquids, for instance, can extend to above $300{ }^{\circ} \mathrm{C}$. 
is maintaining a high ionic conductivity when confined in a porous, solid host material. ${ }^{11-13}$

To address this challenge, some efforts have been made to develop the concept of ionogels, materials that can be prepared from a one-pot sol-gel synthesis performed by reacting a silica precursor with a strong acid inside an ionic liquid. ${ }^{4-14-16}$ In these ionogels the liquid and the solid phases are intimately mixed but the ionic mobility drops rapidly with the silica content. ${ }^{16}$ However, compared to more classical ionogels based on an organic polymeric network (for instance, poly(methyl methacrylate), PMMA) this drop is less pronounced. ${ }^{17}$ Moreover, precedent studies have focused on a relatively low silica content (below 10 vol\%) and a high ionic liquid loading, which result in transport properties very close to those observed in the bulk liquid. ${ }^{18}$ Nevertheless, for practical applications another important property of the ionogel is the mechanical strength, which can be improved with a higher silica content at the expense, however, of a more pronounced loss in ionic mobility.

We have recently demonstrated that the mobility loss in silica-supported ionogels can be reduced by using a new type of silica as the solid bearing structure, i.e. nanoporous silica micro-particles specifically designed to withstand extremely high pressures. ${ }^{19}$ Diffusion NMR experiments have revealed that compared to the previous (sol-gel derived) ionogels, in these gels the mobility loss due to confinement is significantly reduced from $58 \%$ to $25 \%$ of the bulk value. ${ }^{20}$ We have also verified by detailed spectroscopic studies including nuclear magnetic resonance (NMR), Raman and infrared, that the origin of this loss is related to surface interactions established at the ionic liquid/silica interface, i.e. at the pore walls. Manipulating the surface chemistry of silica is therefore a valuable approach in the attempt to further reduce the drop in ionic mobility and to keep liquid-like transport properties even in the solid state. One effort in this direction has been reported by Iacob and co-workers, ${ }^{11}$ who have indeed observed an increase in the self-diffusion of the aprotic ionic liquid 1-hexyl-3-methylimidazolium hexafluorophosphate $\left(\mathrm{C}_{6} \mathrm{C}_{1} \mathrm{ImPF}_{6}\right)$ when immobilized in silanized silica nano-pores (pore size of $7.5 \mathrm{~nm}$ ) as compared to untreated nano-pores. These pores, however, were poorly connected due to an average pore-to-pore distance in the order of $50 \mathrm{~nm}$. The same authors later reported an increase in mobility by two orders of magnitude for the ionic liquid 1-butyl3-methylimidazolium tetrafluoroborate $\left(\mathrm{C}_{4} \mathrm{C}_{1} \mathrm{ImBF}_{4}\right)$ when confined in silica nano-pores with diameters varying between 7.5 and $10.4 \mathrm{~nm}^{21}$ This effect was explained by density changes in the nano-sized domains, but was observed only at very low temperatures (at about $-90{ }^{\circ} \mathrm{C}$ ), not at focus for technological applications. Surprisingly, the possibility that an altered phase behavior due to nano-confinement (for example, a change in the ionic liquid's $T_{\mathrm{g}}$ ) could be at the origin of this enhancement was not discussed. Functionalization of silica has also been proposed to immobilize the negatively charged species of the ionic liquid and thus increase the lithium transference number to target applications in Li-ion batteries. ${ }^{22}$

In this contribution we present a new type of ion-conducting gel that builds upon recent results obtained with nanoporous silica micro-particles filled with an ionic liquid, where the silica structure is designed to provide extremely well-connected nanopores, very good mechanical properties, and a high surface area. $^{20}$ We here demonstrate by different experimental techniques that the ionic mobility is significantly enhanced by chemical functionalization of the silica surface, and we also present a molecular level explanation based on a flipped-ion effect. By validating these results for two very different ionic liquids, one protic short-chained and one aprotic long-chained, we demonstrate that the positive effect on ionic mobility is of general validity. We underline that this material concept, based on micro-sized silica particles with an internal extended porosity on the nanometer scale and good resistance to high pressures, is of fundamental as well as of technological interest. More precisely, these ionogels are of the highest relevance for applications where solid-state electrolytes are desirable, such as Li-ion batteries and PEM fuel cells.

\section{Experimental section}

\subsection{Materials}

The ionic liquids diethyl-methyl-ammonium methanesulfonate (DEMAOMs) and 1-methyl-3-hexylimidazolium bis(trifluoromethanesulfonyl)imide $\left(\mathrm{C}_{6} \mathrm{C}_{1}\right.$ ImTFSI $)$ were purchased from IOLITEC and kept in the inert atmosphere of an argon filled glove box before usage. The molecular structure and the proton labeling of DEMAOMs and $\mathrm{C}_{6} \mathrm{C}_{1}$ ImTFSI, as well as a cartoon of a functionalized silica surface, are shown in Fig. $1.1 \mathrm{D}^{13} \mathrm{C}$ and ${ }^{1} \mathrm{H}$ NMR spectra of the two ionic liquids are given in Fig. S1 $(\mathrm{ESI} \dagger)$.

\subsection{Preparation of the silica gels}

The nanoporous silica micro-particles, with an average particle size of $13 \mu \mathrm{m}$ and an average pore diameter of $10 \mathrm{~nm}$, were prepared via an "Emulsion Solvent Evaporation" method as described in more detail elsewhere. ${ }^{19}$ A SEM image of this kind of particle has already been provided by us in ref. 20 . Then, calculated amounts of nanoporous silica and DEMAOMs or

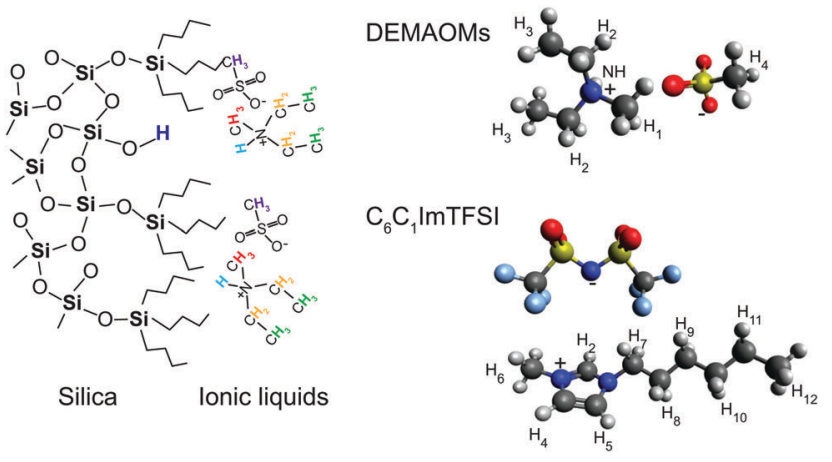

Fig. 1 Left: Cartoon showing a functionalized silica surface interacting with an ionic liquid. Right: Molecular structure of the protic ionic liquid diethylmethylammonium methanesulfonate (DEMAOMs) and of the aprotic ionic liquid 1-hexyl-3-methylimidazolium bis(trifluoromethanesulfonyl)imide $\left(\mathrm{C}_{6} \mathrm{C}_{1}\right.$ ImTFSI). 
$\mathrm{C}_{6} \mathrm{C}_{1}$ ImTFSI were dissolved in $3 \mathrm{~mL}$ of ethanol (see Table $\mathrm{S} 1$ in the ESI $\dagger$ ). These mixtures were stirred for 1 hour, and then kept aside for 1-2 hours to let the ethanol evaporate. These silica gels were then dried at $80{ }^{\circ} \mathrm{C}$ for 24 hours to remove the remaining traces of ethanol and were then sealed in glass vials or NMR tubes for further characterization. The complete elimination of ethanol was routinely verified by NMR spectroscopy and only spectroscopically neat gels were considered for further characterization. The different ionic liquid-to-silica ratios are represented by either $\phi \mathrm{SiO}_{2}$, the volume fraction of silica, or the pore filling factor (given in \%), that is the portion of the total available pore volume actually filled by the ionic liquid. Accordingly, when the pore filling factor is higher than $100 \%$, the ionic liquid is assumed to completely fill the pores and also the inter-particle space.

\subsection{Raman spectroscopy}

Raman spectra were collected with a Renishaw InVia Reflex Raman spectrometer equipped with a CCD detector and using the $785 \mathrm{~nm}$ wavelength from a near infrared diode laser for the excitation. The nominal spectral resolution achieved using this monochromatic light and a 1200 lines per $\mathrm{mm}$ grating was better than $1 \mathrm{~cm}^{-1}$. When collecting Raman spectra the laser power was chosen to be 100 or $50 \%$ of its maximum value, which is $300 \mathrm{~mW}$ at the source. The Raman spectra of the pure ionic liquids and the silica/ionic liquid gels were collected at room temperature with an acquisition time of 10 seconds and averaged over 5 accumulations.

\subsection{Solid-state NMR}

One-dimensional (1D) ${ }^{1} \mathrm{H},{ }^{29} \mathrm{Si}$, and ${ }^{13} \mathrm{C}$ and two-dimensional (2D) ${ }^{29} \mathrm{Si}\left\{{ }^{1} \mathrm{H}\right\}$ and ${ }^{13} \mathrm{C}\left\{{ }^{1} \mathrm{H}\right\}$ HETCOR NMR experiments were performed at room temperature on a Varian Inova-600 NMR spectrometer under a magnetic field of $14.1 \mathrm{~T}$ operating at Larmor frequencies of 600.130, 119.229 and $150.903 \mathrm{MHz}$ for ${ }^{1} \mathrm{H},{ }^{29} \mathrm{Si}$ and ${ }^{13} \mathrm{C}$, respectively, using a $3.2 \mathrm{~mm}{ }^{1} \mathrm{H} / \mathrm{X}$ MAS probehead. 1D quantitative ${ }^{29} \mathrm{Si}$ NMR spectra of untreated and non-functionalized nanoporous silica were collected for 192 scans with a $400 \mathrm{~s}$ recycling delay, while the ${ }^{29} \mathrm{Si}\left\{{ }^{1} \mathrm{H}\right\}$ CP MAS spectra were collected over 2048 scans with 2 s of recycling delay at a MAS rate of $10 \mathrm{kHz}$. The ${ }^{1} \mathrm{H}$ MAS NMR spectra of all silica gels were acquired with 16 scans and $5 \mathrm{~s}$ of recycling delay. The 2D ${ }^{13} \mathrm{C}\left\{{ }^{1} \mathrm{H}\right\}$ HETCOR NMR spectra of functionalized silica gels were recorded by using a minimum of 96 scans with $2 \mathrm{~s}$ of recycling delay, where the signal was accumulated over 128 transients in the F1 dimension. The $2 \mathrm{D}{ }^{29} \mathrm{Si}\left\{{ }^{1} \mathrm{H}\right\}$ HETCOR NMR spectra of functionalized and untreated silica gels were collected over 64 increments in the F1 dimension, using a minimum of 96 scans and $2.5 \mathrm{~s}$ of recycling delay. 1D and 2D ${ }^{29} \mathrm{Si}\left\{{ }^{1} \mathrm{H}\right\}$ and ${ }^{13} \mathrm{C}\left\{{ }^{1} \mathrm{H}\right\}$ NMR experiments were performed using RAMP-CP to fulfill the Hartmann-Hahn condition with a crosspolarization (CP) contact time of $5 \mathrm{~ms}$ or $8 \mathrm{~ms}$, under spinal proton decoupling at a nutation frequency of $90 \mathrm{kHz} .{ }^{1} \mathrm{H},{ }^{29} \mathrm{Si}$, and ${ }^{13} \mathrm{C}$ chemical shifts were externally referenced to a standard TMSP with respect to tetramethylsilane (TMS).

\subsection{PFG NMR}

Diffusion NMR experiments were performed at room temperature $\left(25^{\circ} \mathrm{C}\right)$ on a Bruker Avance II NMR spectrometer under a magnetic field of 14.1 $\mathrm{T}$ operating at a ${ }^{1} \mathrm{H}$ Larmor frequency of 600.130 MHz. Bipolar gradients were used in the pulse sequence in order to suppress the magnetic field susceptibility effects. The signal decay was achieved over 16 steps at a maximum gradient strength of $1200 \mathrm{G} \mathrm{cm}^{-1}$ and at different $\Delta$ (50 or $100 \mathrm{~ms}$ ) and $\delta(1$ or $1.5 \mathrm{~ms}$ ) values. The self-diffusion coefficients, $D$, were then extracted by fitting the echo signal decay with the Stejskal-Tanner expression $I=I_{0} \cdot \exp -\left[(\gamma \delta G)^{2} \cdot D \cdot(\Delta-\delta / 3)\right]$, where $I$ is the signal intensity, $I_{0}$ is the signal intensity of spin-echo at zero gradient, $G$ is the gradient strength, $\delta$ is the length of the gradient pulse, and $\Delta$ is the diffusion time.

\subsection{Impedance spectroscopy}

The temperature dependence of the ionic conductivity was determined by dielectric spectroscopy using a Novocontrol broadband dielectric spectrometer in the frequency range $10^{-2}-10^{7} \mathrm{~Hz}$. The sample was placed between two stainless steel electrodes with a Teflon spacer (with a diameter of $13.3 \mathrm{~mm}$ and a thickness of $1.1 \mathrm{~mm}$ ) and loaded into a cryo-furnace. Data were collected in steps of $10{ }^{\circ} \mathrm{C}$ in three ramp intervals: from 25 to $-5{ }^{\circ} \mathrm{C}$, from -40 to $140{ }^{\circ} \mathrm{C}$ and from 135 to $25{ }^{\circ} \mathrm{C}$, respectively. The temperature equilibration time was set to 10 minutes. The dc conductivity was extracted from the plateau in the frequency dependent conductivity plot.

\section{Results and discussion}

\subsection{Chemistry of nanoporous silica micro-particles: solid-state NMR spectroscopy}

The nanoporous silica micro-particles were either used as untreated, thus kept hydrophilic, or functionalized with butyl groups, namely with tributylsilyl (TBS) to generate hydrophobic surfaces. With this functionalization the contribution from van der Waals interactions is expected to enhance, as opposed to hydrophilic silica in which Coulombic forces or $\mathrm{H}$-bonding dominate. The $1 \mathrm{D}{ }^{1} \mathrm{H},{ }^{13} \mathrm{C}$ and ${ }^{29} \mathrm{Si}$ NMR spectra of the untreated and functionalized silica particles confirm that the functionalization by TBS groups was successful, Fig. $2(\mathrm{a}-\mathrm{c}) .^{23-26}$ This is further confirmed by the absence in functionalized silica of the intense and sharp $\mathrm{H}_{2} \mathrm{O}$ peak at $3.6 \mathrm{ppm}$, reflecting its hydrophobicity and resilience to adsorb water molecules. ${ }^{27}$ Fig. 2c reveals that the distribution of $\mathrm{Q}^{n}{ }^{29} \mathrm{Si}$ species (where $n$ indicates the number of bridging oxygen atoms per Si atom and varies from 0 to 4 ) shifts to a majority of $Q^{4}$ species in functionalized silica, in agreement with the fact that each anchored TBS group brings along an additional $\mathrm{Q}^{4}$ species (see also the cartoon in Fig. 2b). By a more detailed peak fit analysis of the ${ }^{29} \mathrm{Si}$ MAS NMR spectra using the Dmfit program, ${ }^{28}$ we could estimate that untreated silica contains $2 \%$ of $\mathrm{Q}^{2}, 16 \%$ of $\mathrm{Q}^{3}$ and $82 \%$ of $\mathrm{Q}^{4}{ }^{29} \mathrm{Si}$ sites, while functionalized silica consists of $7 \%$ of $\mathrm{Q}^{3}, 84 \%$ of $\mathrm{Q}^{4}$ and $9 \%$ of $\mathrm{TBS}$ ${ }^{29} \mathrm{Si}$ sites. These values suggest that nearly $50 \%$ of the surface 

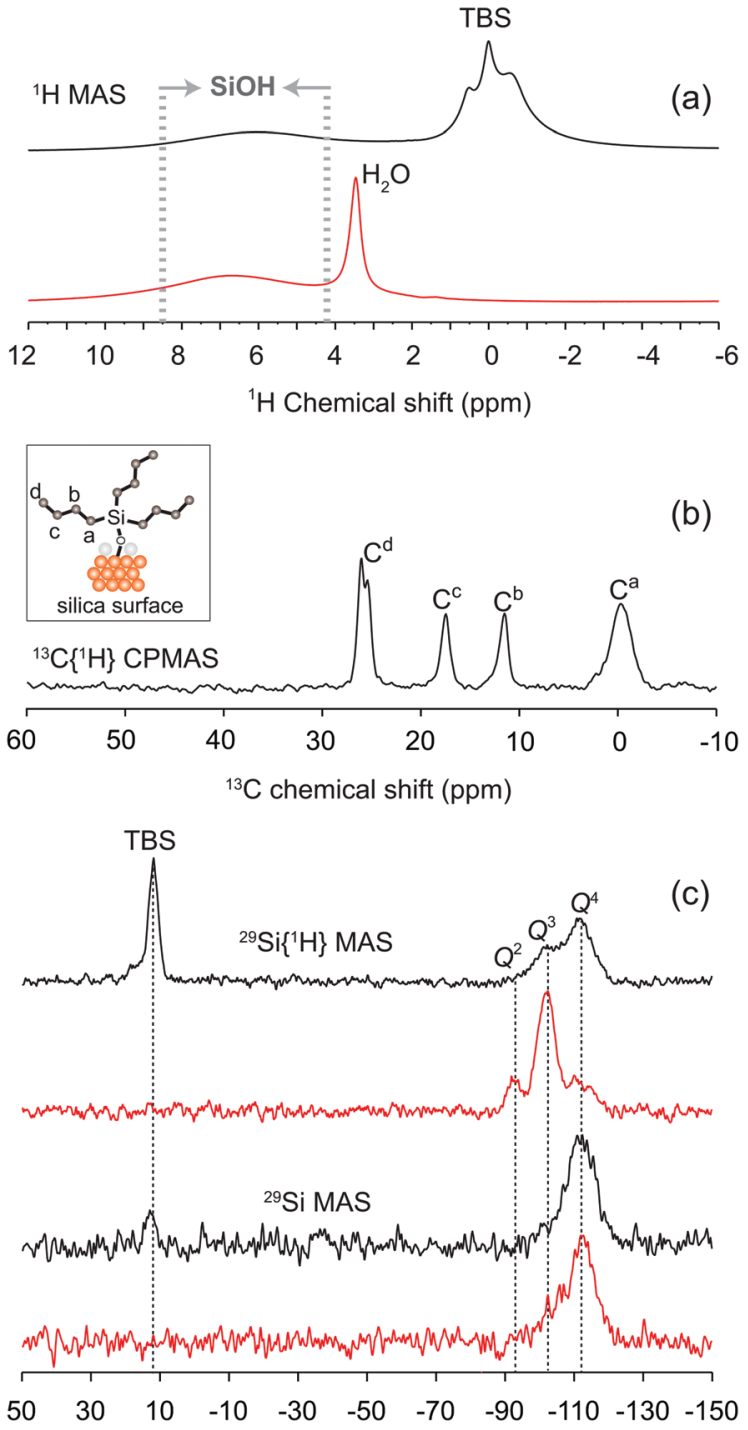

${ }^{29} \mathrm{Si}$ chemical shift (ppm)

Fig. 2 1D ${ }^{1} \mathrm{H}$ MAS (a), ${ }^{13} \mathrm{C}\left\{{ }^{1} \mathrm{H}\right\}$ CPMAS (b) and ${ }^{29} \mathrm{Si} \mathrm{MAS}$ and ${ }^{29} \mathrm{Si}\left\{{ }^{1} \mathrm{H}\right\}$ CPMAS (c) NMR spectra of functionalized (black) and untreated (red) nanoporous silica. These spectra were collected on a $600 \mathrm{MHz}$ Varian solid-state NMR spectrometer at a MAS rate of $10 \mathrm{kHz}$.

${ }^{29} \mathrm{Si}$ sites (i.e. of the $\mathrm{Q}^{2}$ and $\mathrm{Q}^{3}$ species) have been successfully functionalized. In addition, although the TBS chains anchored to the silica surface should be flexible by nature, the width of the ${ }^{13} \mathrm{C}$ NMR features in Fig. $2 \mathrm{~b}$ indicates the occurrence of non-negligible ${ }^{13} \mathrm{C}-{ }^{1} \mathrm{H}$ heteronuclear dipolar interactions.

\subsection{Ionic mobility in the bulk and confined states}

The core of this study is to investigate the effect of surface functionalization on the ionic mobility. To achieve a thorough insight into the mechanism of ionic motion we have therefore employed different complementary techniques, namely: solidstate NMR spectroscopy at different spinning rates to analyze line narrowing effects, diffusion NMR to estimate the selfdiffusion coefficient of the ionic species, and dielectric spectroscopy
Untreated

Functionalized

(a)

(b)

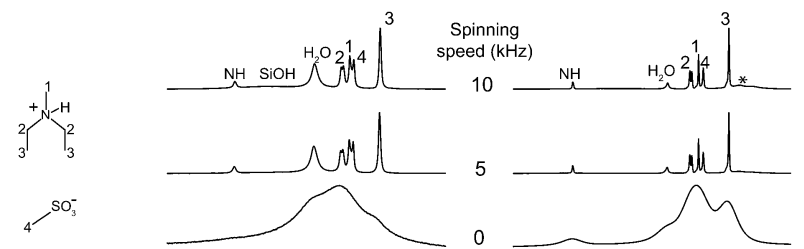

(c)

(d)

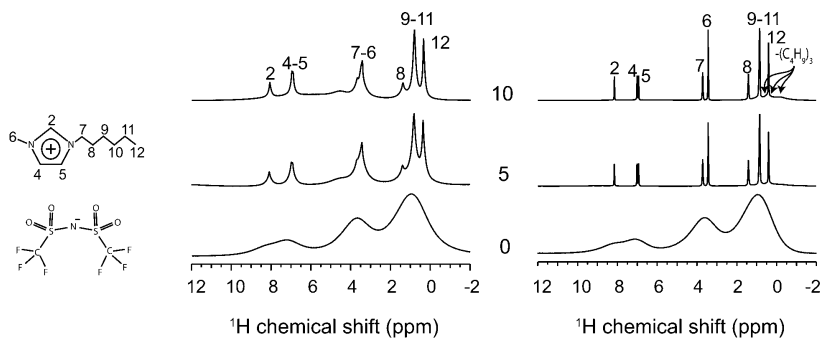

Fig. $3{ }^{1} \mathrm{H}$ solid-state NMR spectra of DEMAOMs (a and b) and $\mathrm{C}_{6} \mathrm{C}_{1}$ ImTFSI ( $c$ and $d$ ) confined in untreated ( $a$ and $c$ ) and functionalized ( $b$ and $d$ ) nanoporous silica (with $\phi \mathrm{SiO}_{2}=0.68$ ). NMR spectra were collected under a magnetic field of $14.1 \mathrm{~T}$ and MAS rates of 0,5 and $10 \mathrm{kHz}$.

to investigate the temperature dependence of the ionic conductivity. Hence the behavior of the ionic liquid while confined in nanoporous silica is compared to that of the bulk state, as discussed in the following sections.

Line narrowing effects. It is well known that the line width in ${ }^{1} \mathrm{H}$ NMR spectra reflects the mobility of the probed molecular species, ${ }^{20,29}$ and in general narrower lines indicate a greater mobility as a result of weaker dipole-dipole interactions. ${ }^{30}$ The strength of these interactions can be probed by varying the magic angle spinning (MAS) rate in solid-state NMR experiments, but cannot be averaged out in solid-like materials under static conditions. The ${ }^{1} \mathrm{H}$ solid-state NMR spectra collected for different gels (at $\phi \mathrm{SiO}_{2}=0.68$ ) and at different spinning rates are shown in Fig. 3. For both ionic liquids the lines become narrower for higher spinning rates, as expected, but these are systematically narrower when the ionic liquid is confined in functionalized silica particles. $\S$ In addition, the ${ }^{1} \mathrm{H}$ resonances of the ionic liquid are always narrower than those of the TBS groups confirming once again that the butyl groups are anchored and stiff, while the ionic liquid molecules are relatively mobile despite the confined state.

Self-diffusion. The self-diffusion coefficients of the ionic liquids' cation, i.e. $\mathrm{DEMA}^{+}$and $\mathrm{C}_{6} \mathrm{C}_{1} \mathrm{Im}^{+}$, obtained from PFG NMR experiments at room temperature are shown in Fig. 4 as a function of the silica content, $\phi \mathrm{SiO}_{2}$. As expected, the selfdiffusion coefficient decreases with $\phi \mathrm{SiO}_{2}$, that is with a higher degree of confinement. ${ }^{16,20}$ For the ionic liquid $\mathrm{C}_{6} \mathrm{C}_{1}$ ImTFSI, we observe that the decrease in self-diffusion is less pronounced in this type of gel than in the gels prepared via the sol-gel route

$\S$ The FWHM is 3 to 4 times narrower than that of untreated silica, e.g. $30 \mathrm{~Hz}$ compared to $100 \mathrm{~Hz}$ for the $\mathrm{H}^{12}$ protons. 

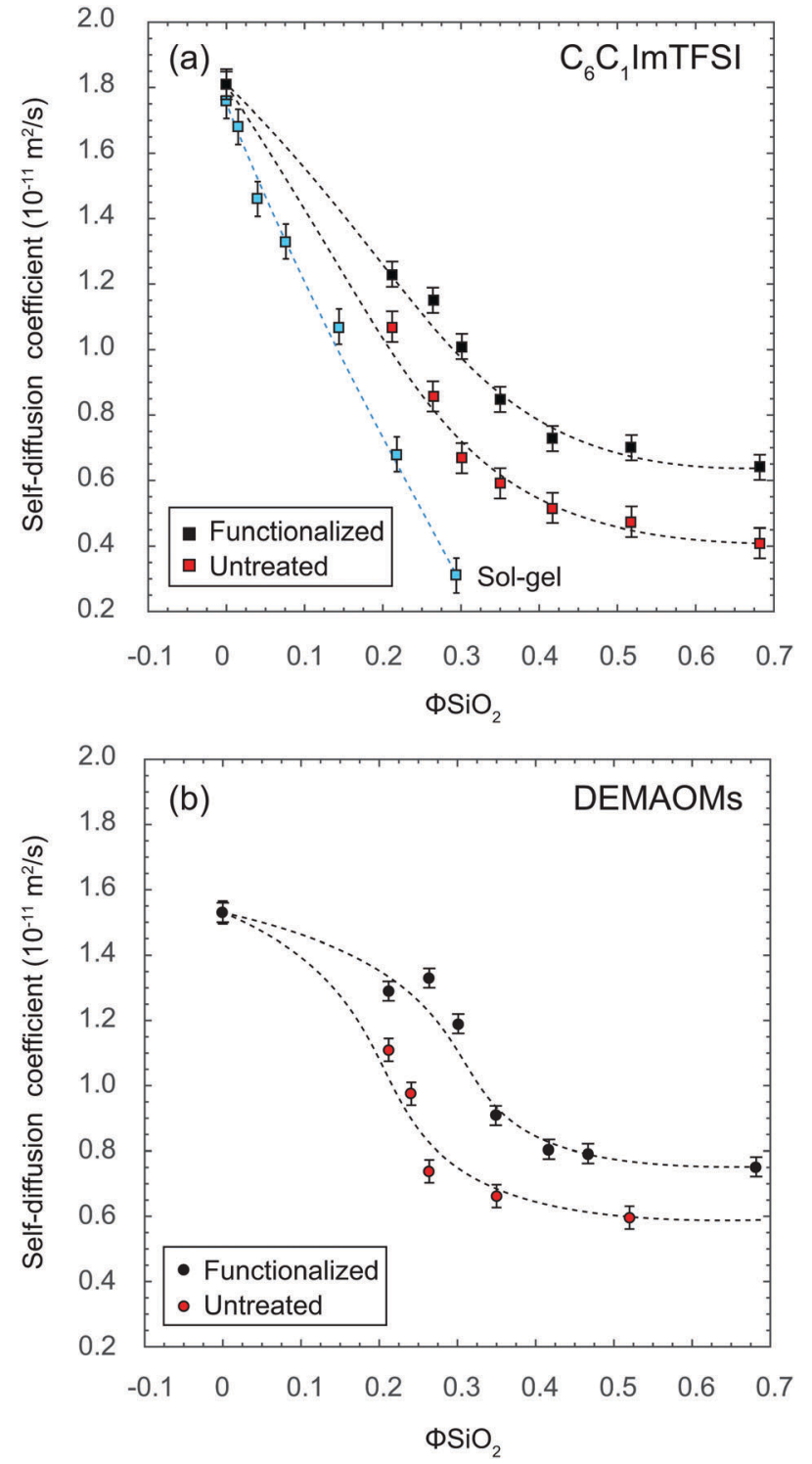

Fig. 4 Self-diffusion coefficients measured in bulk ionic liquids $\left(\phi \mathrm{SiO}_{2}=\right.$ $0)$ and silica gels $\left(\phi \mathrm{SiO}_{2}>0\right)$ by ${ }^{1} \mathrm{H}$ PFGSTE NMR spectroscopy using bipolar gradients for the case of $\mathrm{C}_{6} \mathrm{C}_{1}$ ImTFSI (a) and DEMAOMs (b) while confined in untreated (red) and functionalized (black) nanoporous silica. For comparison, diffusion values previously obtained by us and reported elsewhere ${ }^{16}$ for $C_{6} C_{1}$ ImTFSI inside a sol-gel derived silica are also reported in (a) (blue symbols). The dashed lines are guides for the eye.

previously investigated, ${ }^{16}$ Fig. 4 a. As discussed by us in a recent paper, ${ }^{20}$ this improvement is partly explained by the lower surface area provided by these nanoporous silica micro-particles and thus to a lesser contribution from surface interactions. It is also worth noting that the self-diffusion coefficients are systematically higher when the ionic liquid is confined in functionalized silica as compared to untreated silica, in agreement with the line narrowing effects discussed above, and in line with the hypothesis of weaker surface interactions when van der Waals forces dominate. Another interesting observation is that compared to the bulk diffusion value (see $\phi \mathrm{SiO}_{2}=0$ ), the decrease in mobility with $\phi \mathrm{SiO}_{2}$ is less pronounced for DEMAOMs than for
$\mathrm{C}_{6} \mathrm{C}_{1}$ ImTFSI. More precisely, the maximum loss measured for DEMAOMs in functionalized silica is $46 \%$ of the bulk value (Fig. 4b), whereas for $\mathrm{C}_{6} \mathrm{C}_{1}$ ImTFSI, it is closer to $67 \%$ (Fig. $4 \mathrm{a}$ ). This difference may arise from the ion size effect $\left(\mathrm{DEMA}^{+}<\right.$ $\mathrm{C}_{6} \mathrm{C}_{1} \mathrm{Im}^{+}$and $\mathrm{OMs}^{-}<\mathrm{TFSI}^{-}$) that predicts a more pronounced 'restricted diffusion' when the molecular-to-pore radius ratio exceeds $0.1 .^{31}$ The magnitude of the mobility drop that we report is comparable with that recently reported by Hazelbaker et al., ${ }^{32}$ who have observed a reduction by a factor of two for the self-diffusion of an imidazolium ionic liquid confined in mesoporous silica with pores larger than $5 \mathrm{~nm}$. Apart from the extreme points investigated, i.e. $\phi \mathrm{SiO}_{2}=0.68$ that corresponds to the surface bound ionic liquid and $\phi \mathrm{SiO}_{2}=0.0$ that corresponds to the bulk ionic liquid, the intermediate points represent averaged self-diffusion values that include both these cases. The consistently higher values in functionalized silica throughout the investigated range may indicate a facilitated exchange between surface bound and bulk ionic liquid molecules as compared to the case of non-functionalized silica.

Ionic conductivity. The ionic conductivity, $\sigma$, of DEMAOMs and $\mathrm{C}_{6} \mathrm{C}_{1}$ ImTFSI in the bulk state and when immobilized in functionalized silica has been investigated as a function of temperature by dielectric spectroscopy, Fig. 5a and b. Both ionic liquids reveal a Vogel-Fulcher-Tammann (VFT) dependence between -10 and $140{ }^{\circ} \mathrm{C}$ (see solid lines, i.e. the fit to the experimental data), which suggests a charge transport mechanism strongly associated with the molecular dynamics, i.e. a vehicular mechanism. This behavior typically occurs in bulk ionic liquids and has also been observed in some ionic liquid-based organic and inorganic gels., ${ }^{41,18,33-35}$ The VFT behavior is also observed in our gels, for both silica concentrations investigated, which correspond to values of $\phi \mathrm{SiO}_{2}$ equal to 0.21 and 0.35 or a pore filling factor equal to $200 \%$ and $100 \%$. As expected, a decrease in conductivity is observed with an increasing volume fraction of silica (or a decreasing pore filling factor). However, to eliminate concentration effects it is more rigorous to discuss the dependence of the molar conductivity $\Lambda_{\mathrm{m}}$, which is defined as $\Lambda_{\mathrm{m}}=\sigma / c$ (where $c$ has the units of $\mathrm{mol} \mathrm{cm}{ }^{-3}$ ) and directly relates to the self-diffusion through the Nernst-Einstein equation $\Lambda_{\mathrm{m}}=D z^{2} F^{2} / R T$. The molar conductivities so found are shown in the inset plots of Fig. $5 \mathrm{a}$ and $\mathrm{b}$ (note the logarithmic scale on the $y$-axis) and reveal a strong dependence on the pore filling factor when the ionic liquids are confined in untreated silica. By contrast, and in agreement with the results obtained from solid-state and diffusion NMR, the molar conductivity has a much weaker dependence on the pore filling factor in functionalized silica. Strikingly, in this case an enhancement in conductivity of one order of magnitude is observed for the $100 \%$ filled gels, for both the protic and aprotic ionic liquids, indicating that surface functionalization is the main origin of this effect. As opposed to previously reported results, ${ }^{21}$ this enhancement is observed in the whole temperature range investigated (from -10 to $140{ }^{\circ} \mathrm{C}$ ), and is not limited to very low temperatures that are not of technological interest. 

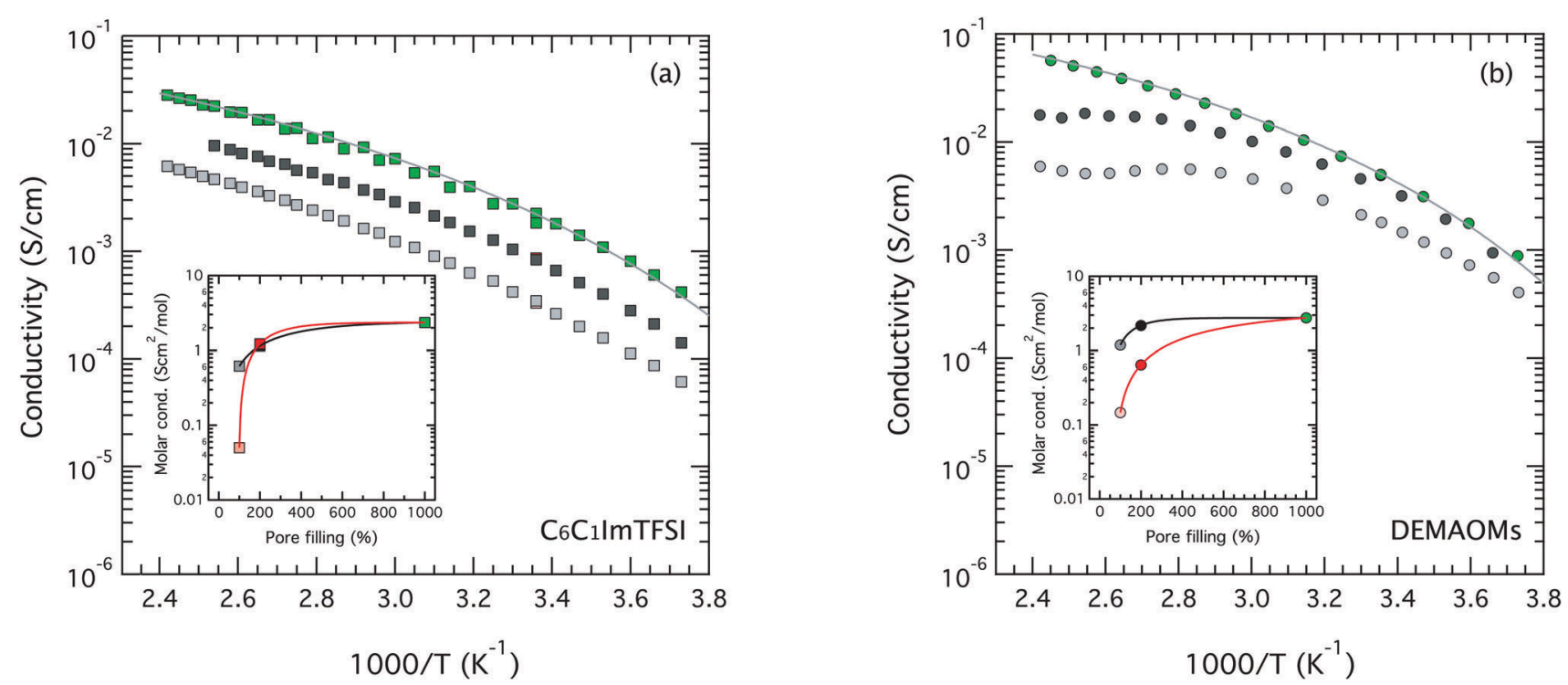

Fig. 5 Ionic conductivity measured for the aprotic ionic liquid $\mathrm{C}_{6} \mathrm{C}_{1} \mathrm{ImTFSI}(\mathrm{a})$ and the protic ionic liquid DEMAOMs (b) in the bulk/liquid state (green), and in the gel state when confined in functionalized silica (black and gray). lonogels with a pore filling factor equal to $200 \%$ (i.e. $\left.\phi \mathrm{SiO}_{2}=0.21\right)$ and $100 \%$ (i.e. $\phi \mathrm{SiO}_{2}=0.35$ ) are represented by black and gray symbols, respectively. Inset: Molar conductivity (i.e. the conductivity normalized to the volume fraction actually occupied by the ionic liquid in the gel) estimated from conductivity data at $60{ }^{\circ} \mathrm{C}$ (i.e. at $1000 / T \simeq 3.0$ ) as a function of the pore filling factor for ionogels based on untreated (red/pink) and functionalized (black/gray) silica. The data points for the bulk ionic liquids are shown as a pore filling factor equal to 1000 (instead of infinity) for an easier visualization of the trends. Solid lines in the inset figures are a guide for the eye.

However, while the conductivity of $\mathrm{C}_{6} \mathrm{C}_{1}$ ImTFSI shows similar temperature dependences in the bulk and in the nano-confined state, the conductivity of DEMAOMs in the gel state shows a deviation from the bulk values upon heating. The ionic conductivity being lower than expected by the VFT behavior is most likely due to poor thermal stability of this specific protic ionic liquid. In this respect, we have recently reported a thermal decomposition for pure DEMAOMs where dehydration precedes the back transfer of the protons from $\mathrm{DEMA}^{+}$to $\mathrm{OMs}^{-}$with the consequent evaporation of neutral amine species. ${ }^{36}$ As shown in Fig. 5b, the conductivity in functionalized silica deviates from the expected VFT behavior above $\sim 85^{\circ} \mathrm{C}$ (or below 1000/T $=2.8$ ), which is also the temperature for a first mass loss phenomenon detected by TGA for the corresponding gel (Fig. S2, ESI $\dagger$ ). ${ }^{36}$ This observation suggests that for the specific need of hightemperature applications, e.g. in next-generation fuel cells operating above $120{ }^{\circ} \mathrm{C}$, a protic ionic liquid more thermally stable than DEMAOMs should be selected. By contrast, the TGA results of the gels containing $\mathrm{C}_{6} \mathrm{C}_{1}$ ImTFSI show a thermal stability extending to above $300{ }^{\circ} \mathrm{C}$. The observation of a similar thermal stability for ionic liquids in the bulk and the nanoconfined state is in agreement with the findings reported in other previous studies focused on nanoporous silica with pore sizes equal to or larger than $10 \mathrm{~nm}^{7}$

Another interesting aspect of the materials presented in this study is that due to the extremely high and well-connected porosity of the silica particles non-flowing gels can be obtained even at a very high ionic liquid loading, thus securing high ionic conductivity. This is shown in Fig. 6, in which the ionic conductivity displayed by several gel-state electrolytes is compared with that of the bulk liquid analogues. This figure reveals

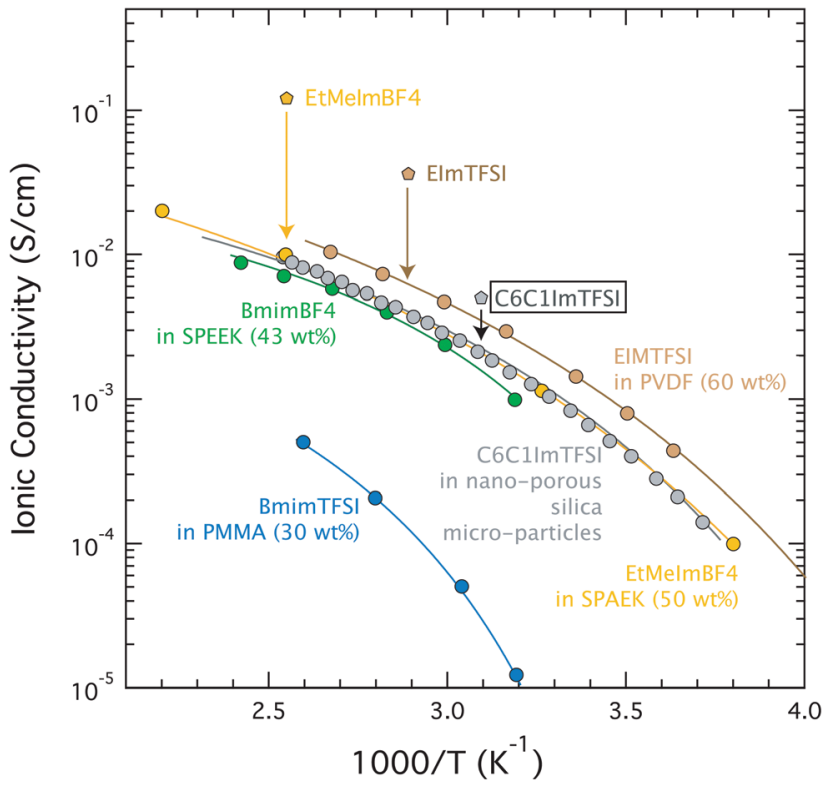

Fig. 6 Comparative plot with the ionic conductivity displayed by various ionic liquids in the bulk (hexagons) and the gel (circles) state: 1-ethyl-3methylimidazolium-BF 4 in SPAEK, ${ }^{37}$ 1-butyl-3-methylimidazolium- $\mathrm{BF}_{4}$ in SPEEK, ${ }^{38}$ ethylimidazolium-TFSI in PVdF, ${ }^{35}$ 1-butyl-3-methylimidazoliumTFSI in PMMA, ${ }^{39}$ and 1-hexyl-3-methylimidazolium-TFSI in nanoporous silica micro-particles (this work, $200 \%$ pore filling). The drop in conductivity observed from the bulk to the gel state is represented, when data are available, by a vertical arrow.

that the difference in conductivity observed between the bulk $\mathrm{C}_{6} \mathrm{C}_{1}$ ImTFSI and its (non-flowing) gel based on $200 \%$ pore filling is very small and, to the best of our knowledge, the 
smallest when compared to other reported ionic liquid based gel systems (compare vertical arrows). ${ }^{35,37-39}$

To summarize, solid-state NMR, diffusion NMR and dielectric experiments all confirm that surface functionalization results in a significant enhancement of the ionic mobility for the ionic liquid confined in a nano-sized domain. Most importantly, this is true for both an imidazolium aprotic ionic liquid such as $\mathrm{C}_{6} \mathrm{C}_{1}$ ImTFSI and an ammonium protic ionic liquid like DEMAOMs, which points to the general validity of this enhancement effect. With respect to previous results already reported on the subject, our materials also provide an excellent pore connectivity as well as a mobility enhancement at all temperatures investigated, extending to well above $120{ }^{\circ} \mathrm{C}$, the target for future fuel cell devices.

\subsection{Surface interactions and flipped-ion effect}

To achieve a molecular level understanding of the origin of enhanced mobility upon functionalization, we have investigated the nature of intermolecular interactions as well as the molecular orientation at the silica interface. The latter has been monitored by $2 \mathrm{D}$ solid-state ${ }^{29} \mathrm{Si}\left\{{ }^{1} \mathrm{H}\right\}$ and ${ }^{13} \mathrm{C}\left\{{ }^{1} \mathrm{H}\right\}$ heteronuclear correlation (HETCOR) experiments, by which the spatial proximity of ${ }^{1} \mathrm{H}$ nuclei to ${ }^{29} \mathrm{Si}$ or ${ }^{13} \mathrm{C}$ sites can be probed. To emphasize surface effects these experiments were performed solely for silica gels with $\phi \mathrm{SiO}_{2}=0.68$, for which only one layer of ionic liquid is adsorbed onto the silica surface, Fig. $7 .^{20}$ The $2 \mathrm{D}$ patterns obtained for the gels filled with $\mathrm{C}_{6} \mathrm{C}_{1}$ ImTFSI (Fig. 7a) and DEMAOMs (Fig. 7b) reveal strong correlation peaks between the $\mathrm{Q}^{3}$ and $\mathrm{Q}^{4}{ }^{29} \mathrm{Si}$ species and the ${ }^{1} \mathrm{H}$ resonances of the ionic

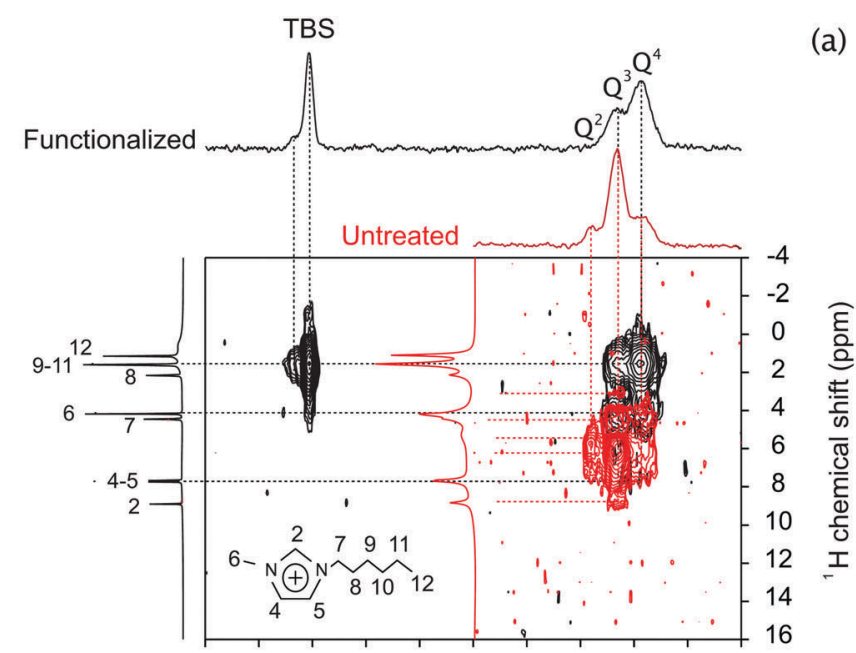

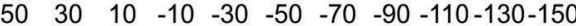

${ }^{29} \mathrm{Si}$ chemical shift (ppm)

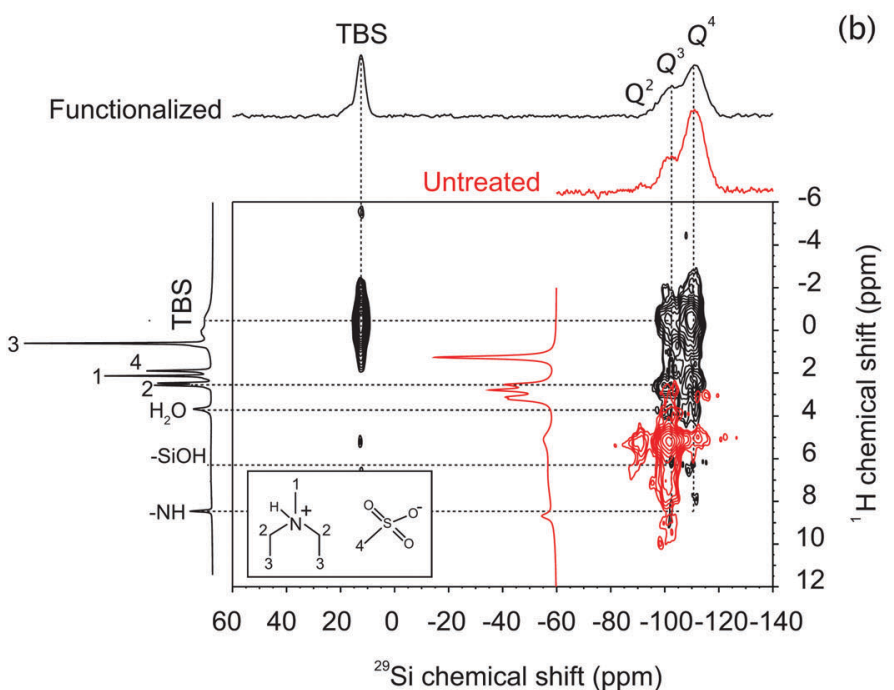

(a)

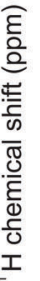

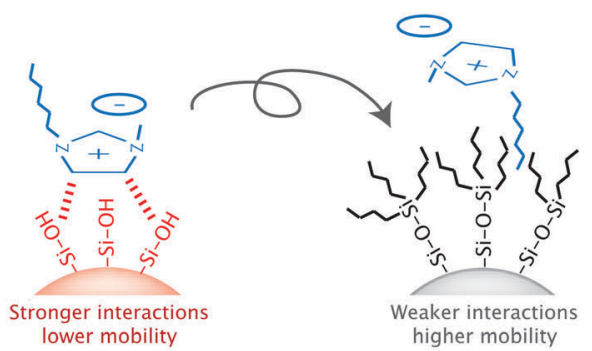

(d)

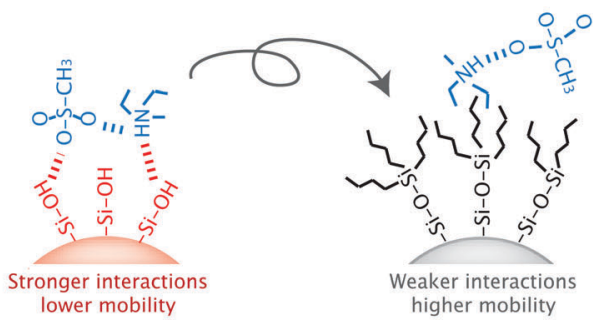

Fig. 7 2D correlation patterns obtained from solid-state ${ }^{29} \mathrm{Si}\left\{{ }^{1} \mathrm{H}\right\}$ HETCOR NMR experiments for a gel containing $\mathrm{C}_{6} \mathrm{C}_{1} \mid \mathrm{mTFSI}$ (a) and a gel containing DEMAOMs (b). The results of untreated and functionalized silica are shown in red and black respectively. In all cases the silica volume fraction was $\phi \mathrm{SiO}_{2}=0.68$. The local orientation and the nature of interactions at the silica interface are shown in (c) and (d) for $\mathrm{C}_{6} \mathrm{C}_{1}$ ImTFSI and DEMAOMs respectively. 
liquid. However, while in untreated silica the correlation clearly involves the $\mathrm{NH}$ group for DEMAOMs and the ring protons for $\mathrm{C}_{6} \mathrm{C}_{1}$ ImTFSI, in agreement with the results reported in recent studies, ${ }^{16,20}$ in functionalized silica, the correlation peaks are shifted to mainly involve the alkyl chains. These 2D patterns thus reveal that in functionalized silica the alkyl groups of $\mathrm{DEMA}^{+}$and $\mathrm{C}_{6} \mathrm{C}_{1} \mathrm{Im}^{+}$are in molecular proximity to the TBS units and the cations are flipped around compared to the case of untreated silica, see cartoons in Fig. 7c and d. Unfortunately, the peaks in the 1-3 ppm range are too close to make a conclusion about the position of the OMs anion. The successful inclusion of the ionic liquid inside the nano-pores of silica, as well as its molecular orientation at the silica interface, has been further confirmed by complementary ${ }^{13} \mathrm{C}\left\{{ }^{1} \mathrm{H}\right\}$ HETCOR NMR experiments, the results of these being shown in Fig. S3 (ESI $\dagger$ ). Interestingly, in the presence of the ionic liquid the ${ }^{13} \mathrm{C}$ peak resonating at $10 \mathrm{ppm}$ and labeled as $\mathrm{C}^{\mathrm{b}}$ splits into two signatures $\mathrm{C}^{\mathrm{b} 1}$ and $\mathrm{C}^{\mathrm{b} 2}$ resonating at 10 and 12 ppm, respectively (Fig. S3a, ESI $\dagger$ ), suggesting that the proximity of $\mathrm{C}_{6} \mathrm{C}_{1}$ ImTFSI to the silica surface in turn also modifies the local environment of the TBS groups.

Further insights into the effect of nano-confinement and functionalization on the intermolecular interactions have been achieved by Raman spectroscopy. In particular, the state of the anion has been investigated analyzing the frequency range where interaction sensitive vibrations are found. More precisely, the expansion-contraction mode of the TFSI anion at $\simeq 742 \mathrm{~cm}^{-1}$ is observed to shift to higher frequencies when $\mathrm{C}_{6} \mathrm{C}_{1}$ ImTFSI is confined in untreated silica, with a major change when the pore filling is lower than $50 \%$ (or $\phi \mathrm{SiO}_{2}>$ 0.52), inset of Fig. 8. This reflects TFSI anions that experience stronger interactions or, as proposed by Coasne et al., ${ }^{40}$ an

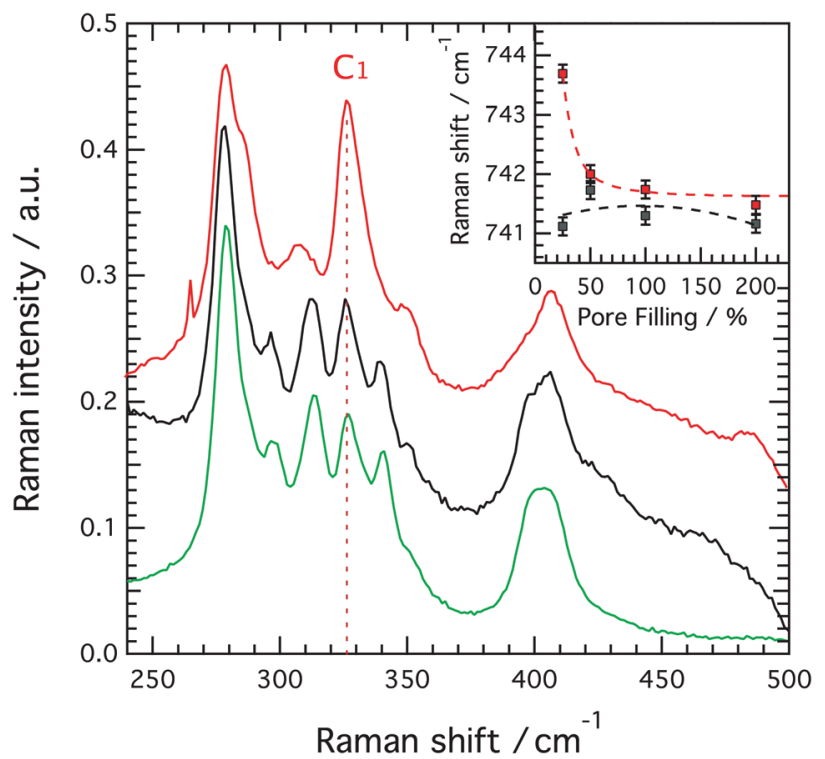

Fig. 8 Raman spectra of pure $\mathrm{C}_{6} \mathrm{C}_{1}$ ImTFSI in the bulk state (green) and when confined in functionalized (black) and untreated (red) silica. The conformational sensitive range $240-500 \mathrm{~cm}^{-1}$ is here at focus. Inset: Raman shift for the expansion-contraction mode of the TFSI as a function of pore filling factor in untreated (red) and functionalized (black) silica. increased local ionic density. Concomitantly, the population of cisoid (or $\mathrm{C}_{1}$ ) conformers increases with $\phi \mathrm{SiO}_{2}$, Fig. 8, in accordance with our previous findings. ${ }^{15,16}$ By contrast, in functionalized silica both the vibrational mode at $\approx 742 \mathrm{~cm}^{-1}$ and the conformational population remain close to the bulk values. The Raman signature of the OMs anion at about $1040 \mathrm{~cm}^{-1}$ increases in frequency with $\phi \mathrm{SiO}_{2}$ in a similar manner in both functionalized and untreated silica, ${ }^{20}$ Fig. S4 (ESI $\dagger$ ). Thus, the results shown in Fig. 7 and 8 reveal that while both the DEMA and $\mathrm{C}_{6} \mathrm{C}_{1}$ Im cations are flipped around at the solid interface in functionalized silica, the OMs anion, as opposed to TFSI, remains almost unaffected by this re-orientation. This may be explained by the stronger and more specific cationanion interactions established in DEMAOMs ${ }^{36}$ as opposed to the case of $\mathrm{C}_{6} \mathrm{C}_{1}$ ImTFSI and, as mentioned above, by the smaller ionic size of $\mathrm{DEMA}^{+}$and $\mathrm{OMs}^{-}{ }^{-41}$

Additional structural information is obtained from DSC experiments, which show an altered phase behavior of the ionic liquids upon nano-confinement. In particular, the crystallization upon cooling and thus the subsequent melting upon heating are suppressed in $100 \%$ filled gels, i.e. when the liquid is constrained in nano-sized domains. Moreover while DEMAOMs displays glass transition temperatures $\left(T_{\mathrm{g}}\right)$ below $-95{ }^{\circ} \mathrm{C}$ (and thus not detectable under our accessible experimental conditions), $\mathrm{C}_{6} \mathrm{C}_{1}$ ImTFSI reveals $T_{\mathrm{g}}$ values around $-84{ }^{\circ} \mathrm{C}$ slightly depending on the composition and with a tendency to lower values for higher degrees of confinement, Fig. S5 (ESI $\dagger$ ). A decrease of $T_{\mathrm{g}}$ upon confinement in nanoporous silica was also observed by Singh et $\mathrm{al}^{42}$ for the ionic liquid 1-butyl-3-methylimidazolium octyl sulfate $\left(\mathrm{BMIM}-\mathrm{OcSO}_{4}\right)$, and explained by a complex wall-ionic liquid interaction by which the density at the silica surface is expected to increase and the density in the center of the pores to decrease. The resulting decrease in $T_{\mathrm{g}}$, however, is limited to only a few degree Celsius, in accordance with what we observe in this work.

\section{Conclusions}

This work presents the performance of a new type of ionconducting material based on specially designed nanoporous silica micro-particles subsequently filled by an ionic liquid. We demonstrate that the chemical surface functionalization of the silica pore walls by tributylsilyl groups has the effect of enhancing the overall ionic mobility of the ionic liquid residing in the nano-sized pores. This enhancement is demonstrated for two very different ionic liquids, one protic ammonium based and representative of next-generation electrolytes for PEM fuel cells, and one aprotic imidazolium based, a typical electrolyte highlighted for use in future safer Li-ion batteries. By combining the results of several complementary techniques we propose a molecular level mechanism for the enhanced ionic mobility, which is based on decreased ionic liquid-silica interactions and a concomitant flipped-ion effect at the silica interface. The mobility enhancement is particularly evident at high silica volume fractions (that is for pore filling factors below $100 \%$, 
i.e. for the ionic liquid residing inside the nano-sized domains), with the ionic liquid in functionalized silica displaying a conductivity at least one order of magnitude higher than that observed for the case of untreated silica. In addition, the ionic conductivity drop observed when comparing the ionic liquid in the bulk with the gel state is much smaller in the gels proposed here than in other organic or inorganic gels previously investigated. These results underline an important progress in the direction of solid-state electrolytes with liquid-like transport properties. These are of immediate interest for use in energy relevant technologies such as PEM fuel cells or Li-ion batteries, but are also attractive in other scientific fields where controlled delivery and mass transport through restricted domains are critical issues, which include pharmaceutical, food science, and catalysis.

\section{Acknowledgements}

The authors acknowledge the following funding agencies: the Swedish Research Council (VR, grant no 2012-3186, 622-2009388 and 349-2013-605), the Swedish Foundation for Strategic Research (SSF, grant no ICA 10-0074), and the Chalmers Areas of Advance Energy and Materials Science. The Swedish NMR Center is also kindly acknowledged for providing the NMR infrastructure to perform diffusion and solid-state NMR experiments.

\section{References}

1 S. Bernèche and B. Roux, Energetics of Ion Conduction Through the $\mathrm{K}^{+}$Channel, Nature, 2001, 414(6859), 73-77.

2 M. H. Valkenberg, C. DeCastro and W. F. Hölderich, Immobilisation of Ionic Liquids on Solid Supports, Green Chem., 2002, 4(2), 88-93.

3 A. I. Horowitz and M. J. Panzer, Poly(dimethylsiloxane)supported Ionogels With a High Ionic Liquid Loading, Angew. Chem., Int. Ed., 2014, 53(37), 9780-9783.

4 S. A. M. Noor, P. M. Bayley, M. Forsyth and D. MacFarlane, Ionogels Based on Ionic Liquids as Potential Highly Conductive Solid State Electrolytes, Electrochim. Acta, 2013, 91, 219-226.

5 J. Rodriguez, M. D. Elola and D. Laria, Ionic Liquid Aqueous Solutions Under Nanoconfinement, J. Phys. Chem. C, 2012, 116(9), 5394-5400.

6 R. Valiullin, S. Naumov, P. Galvosas, J. Kärger, H.-J. Woo, F. Porcheron and P. A. Monson, Exploration of Molecular Dynamics During Transient Sorption of Fluids in Mesoporous Materials, Nature, 2006, 443(7114), 965-968.

7 M. P. Singh, R. K. Singh and S. Chandra, Ionic Liquids Confined in Porous Matrices: Physicochemical Properties and Applications, Prog. Mater. Sci., 2014, 64, 73-120.

8 M. Dvoyashkin, R. Khokhlov, R. Valiullin and J. Kärger, Freezing of Fluids in Disordered Mesopores, J. Chem. Phys, 2008, 129(15), 154702.
9 M. Armand, F. Endres, D. R. MacFarlane, H. Ohno and B. Scrosati, Ionic Liquid Materials for the Electrochemical Challenges of the Future, Nat. Mater., 2009, 8(8), 621-629.

10 T. Torimoto, T. Tsuda, K. I. Okazaki and S. Kuwabata, New Frontiers in Materials Science Opened by Ionic Liquids, Adv. Mater., 2010, 22(11), 1196-1221.

11 C. Iacob, J. R. Sangoro, P. Papadopoulos, T. Schubert, S. Naumov, R. Valiullin, J. Kärger and F. Kremer, Charge Transport and Diffusion of Ionic Liquids in Nanoporous Silica Membranes, Phys. Chem. Chem. Phys., 2010, 12(41), 13798-13803.

12 J. Le Bideau, P. Gaveau, S. Bellayer, M. A. Neouze and A. Vioux, Effect of Confinement on Ionic Liquids Dynamics in Monolithic Silica Ionogels: ${ }^{1} \mathrm{H}$ NMR Study, Phys. Chem. Chem. Phys., 2007, 9(40), 5419-5422.

13 M. Davenport, A. Rodriguez, K. J. Shea and Z. S. Siwy, Squeezing Ionic Liquids Through Nanopores, Nano Lett., 2009, 9(5), 2125-2128.

14 M.-A. Neouze, J. Le Bideau, P. Gaveau, S. Bellayer and A. Vioux, Ionogels, New Materials Arising From the Confinement of Ionic Liquids Within Silica-Derived Networks, Chem. Mater., 2006, 18(17), 3931-3936.

15 A. Martinelli and L. Nordstierna, An Investigation of the Sol-Gel Process in Ionic Liquid-Silica Gels by Time Resolved Raman and 1H NMR Spectroscopy, Phys. Chem. Chem. Phys., 2012, 14(38), 13216-13223.

16 M. Nayeri, M. A. Aronson, D. Bernin, B. F. Chmelka and A. Martinelli, Surface Effects on the Structure and Mobility of the Ionic Liquid $\mathrm{C}_{6} \mathrm{C}_{1}$ ImTFSI in Silica Gels, Soft Matter, 2014, 10(30), 5618-5627.

17 K. Ueno, K. Hata, K. Katakabe, M. Kondoh and M. Watanabe, Nanocomposite Ion Gels Based on Silica Nanoparticles and an Ionic Liquid: Ionic Transport, Viscoelastic Properties, and Microstructure, J. Phys. Chem. B, 2008, 112(30), 9013-9019.

18 J. Nordström, L. Aguilera and A. Matic, Effect of Lithium Salt on the Stability of Dispersions of Fumed Silica in the Ionic Liquid BMImBF4, Langmuir, 2012, 28(9), 4080-4085.

19 N. Andersson, B. Kronberg, R. Corkery and P. Alberius, Combined Emulsion and Solvent Evaporation (ESE) Synthesis Route to Well-Ordered Mesoporous Materials, Langmuir, 2007, 23(3), 1459-1464.

20 M. N. Garaga, M. Persson, N. Yaghini and A. Martinelli, Local Coordination and Dynamics of a Protic Ammonium Based Ionic Liquid Immobilized in Nano-Porous Silica Micro-Particles Probed by Raman and NMR Spectroscopy, Soft Matter, 2016, 12(9), 2583-2592.

21 C. Iacob, J. R. Sangoro, W. K. Kipnusu, R. Valiullin, J. Kärger and F. Kremer, Enhaned Charge Transport in NanoConfined Ionic Liquids, Soft Matter, 2012, 8(2), 289-293.

22 S. Delacroix, F. Sauvage, M. Reynaud, M. Deschamps, S. Bruyere, M. Becuwe, D. Postel, J. M. Tarascon and A. N. Van Nhien, $\mathrm{SiO}_{2} /$ Ionic Liquid Hybrid Nanoparticles for Solid-State Lithium Ion Conduction, Chem. Mater., 2015, 27(23), 7926-7933.

23 P. Dibandjo, S. Dire, F. Babonneau and G. D. Soraru, Influence of the Polymer Architecture on the High Temperature 
Behavior of SiCO Glasses: A Comparison Between Linearand Cyclic-Derived Precursors, J. Non-Cryst. Solids, 2010, 356(3), 132-140.

24 G. D. Soraru, G. D’Andrea, R. Campostrini, F. Babonneau and G. Mariotto, Structural Characterization and HighTemperature Behavior of Silicon Oxycarbide Glasses Prepared from Sol-Gel Precursors Containing Si-H Bonds, J. Am. Ceram. Soc., 1995, 78(2), 379.

25 M. K. Kolel-Veetil, K. P. Fears, S. B. Qadri, C. A. Klug and T. M. Keller, Formation of Crosslinked POSS Network by an Unusual Hydrosylilation: Thermo-Oxidative Stabilization of the $\alpha$-Cristobalite Phase in its Amorphous Regions, J. Polym. Sci., Part A: Polym. Chem., 2012, 50(15), 3158-3170.

26 W. J. Malfait, S. Zhao, R. Verel, S. Iswar, D. Rentsch, R. Fener, Y. Zhang, B. Milow and M. M. Koebel, Surface Chemistry of Hydrophobic Silica Aerogels, Chem. Mater., 2015, 27(19), 6737-6745.

27 M. Xu, K. D. M. Harris and J. M. Thomas, Mapping the Evolution of Adsorption of Water in Nanoporous Silica by In Situ Solid-State 1H NMR Spectroscopy, J. Am. Chem. Soc., 2008, 130(18), 5880-5882.

28 D. Massiot, F. Fayon, M. Capron, I. King, S. Le Calve, B. Alonso, J.-O. Durand, B. Bujoli, Z. Gan and G. Hoatson, Modelling One- and Two-Dimensional Solid-State NMR Spectra, Magn. Reson. Chem., 2002, 40(1), 70-76.

29 J. Le Bideau, L. Viau and A. Vioux, Ionogels, Ionic Liquid Based Hybrid Materials, Chem. Soc. Rev., 2011, 40(2), 907-925.

30 C. P. Slichter, Principles of Magnetic Resonance, Springer, 3rd edn, 1990.

31 S. R. Veith, E. Hughes, G. Vuataz and S. E. Pratsinis, Restricted Diffusion in Silica Particles Measured by Pulsed Field Gradient NMR, J. Colloid Interface Sci., 2004, 274(1), 216-228.

32 E. D. Hazelbaker, R. Guillet-Nicolas, M. Thommes, F. Kleitz and S. Vasenkov, Influence of Confinement in Mesoporous Silica on Diffusion of a Mixture of Carbon Dioxide and an Imidazolium-Based Ionic Liquid by High Field Diffusion NMR, Microporous Mesoporous Mater., 2015, 206(C), 177-183.

33 J. Pitawala, M. A. Navarra, B. Scrosati, P. Jacobsson and A. Matic, Structure and Properties of Li-ion Conducting Polymer Gel Electrolytes Based on Ionic Liquids of the
Pyrrolidinium Cation and the bis(trifluoromethanesulfonate)imide Anion, J. Power Sources, 2014, 245, 830-835.

34 A. Martinelli, A. Matic, P. Jacobsson, L. Börjesson, A. Fernicola and B. Scrosati, Phase Behavior and Ionic Conductivity in Lithium bis(trifluoromethanesulfonate)imide-Doped Ionic Liquids of the Pyrrolidinium Cation and Bis(trifluoromethanesulfonate)imide Anion, J. Phys. Chem. B, 2009, 113(32), 11247-11251.

35 A. Martinelli, A. Matic, P. Jacobsson, L. Börjesson, A. Fernicola, S. Panero, B. Scrosati and H. Ohno, Physical Properties of Proton Conducting Membranes Based on a Protic Ionic Liquid, J. Phys. Chem. B, 2007, 111(43), 12462-12467.

36 N. Yaghini, M. N. Garaga and A. Martinelli, Transport Properties, Local Coordination, and Thermal Stability of the Water/Diethylmethylammonium Methanesulfonate Binary System, Fuel Cells, 2016, 16(1), 46-54.

37 E. Cho, J.-S. Park, S. S. Sekhon, G.-G. Park, T.-H. Yang, W.-Y. Lee, C.-S. Kim and S.-B. Park, A Study on Proton Conductivity of Composite Membranes with Various Ionic Liquids for High-Temperature Anhydrous Fuel Cells, J. Electrochem. Soc., 2009, 156(2), B197-B202.

38 H. Zhang, W. Wu, J. Wang, T. Zhang, B. Shi, J. Liu and S. Cao, Enhanced Anhydrous Proton Conductivity of Polymer Electrolyte Membranes Enabled by Facile Ionic Liquid-Based Hoping Pathways, J. Membr. Sci., 2015, 476, 136-147.

39 Z. L. Xie, X. Huang and A. Taubert, Dyeionogels: ProtonResponsive Ionogels Based on a Dye-Ionic Liquid Exhibiting Reversible Color Change, Adv. Funct. Mater., 2014, 24(19), 2837-2843.

40 B. Coasne, L. Viau and A. Vioux, Loading-Controlled Stiffening in Nanoconfined Ionic Liquids, J. Phys. Chem. Lett., 2011, 2(10), 1150-1154.

41 M. N. Garaga, M. Nayeri and A. Martinelli, Effect of the Alkyl Chain Length in 1-alkyl-3-methylimidazolium Ionic Liquids on Intermolecular Interactions and Rotational Dynamics: A Combined Vibrational and NMR Spectroscopic Study, J. Mol. Liq., 2015, 210, 169-177.

42 M. P. Singh, R. K. Singh and S. Chandra, Studies on Imidazolium-Based Ionic Liquids Having a Large Anion Confined in a Nanoporous Silica Gel Matrix, J. Phys. Chem. $B, 2011,115,7505-7514$. 